EVIDENCE BASED PUBLIC HEALTH POLICY AND PRACTICE

\title{
Post-disaster health effects: strategies for investigation and data collection. Experiences from the Enschede tirework disaster
}

\author{
J Roorda, W A H J van Stiphout, R R R Huijsman-Rubingh
}

J Epidemiol Community Health 2004;58:982-987. doi: 10.1136/jech.2003.014613

Background: Public health policy is increasingly concerned with the care for victims of a disaster. This article describes the design and implementation of an epidemiological study, which seeks to match care services to the specific problems of persons affected by a large scale incident. The study was prompted by the explosion of a firework depot in Enschede, the Netherlands.

Study population: All those directly affected by this incident (residents, emergency services personnel, and people who happened to be in the area at the time), some of whom suffered personal loss or injury. The project investigates both the physical and psychological effects of the disaster, as well as the target group's subsequent call on healthcare services.

See end of article for authors' affiliations

Study design: A questionnaire based follow up survey of those directly affected and an ongoing monitoring of health problems relying on reports from healthcare professionals. The follow up survey started three weeks after the incident and was repeated 18 months and almost four years after the incident.

Correspondence to: Mr J Roorda, GGD Regio Twente, PO Box 1400, 7500 BK Enschede, Netherlands; j.roorda. ggd@regiotwente.nl The monitoring is conducted over a four year period by general practitioners, the local mental health services department, occupational health services, and the youth healthcare services department. It provides ongoing information.

Results and Conclusions: The results of the study are regularly discussed with healthcare professionals and policy makers, and are made known to the research participants. The paper also explains the considerations that were made in designing the study to help others making up their research plans when 24 April 2004 confronted with possible health effects of a disaster.

$P$ ublic health policy is increasingly concerned with care for the victims of a disaster. ${ }^{1}$ Any major incident will affect large groups of people; the consequences in terms of physical and psychological health, and the ability to function properly in the work or family situation, may be long term in nature. ${ }^{23}$ Proper aftercare services for disaster victims must be fully integrated, meeting their physical, psychological, and social needs. Such services must be organised on a long term basis, not only seeking to deal with actual symptoms and complaints, but also to pre-empt and prevent problems, to promote good health, and to reinstate the fabric of the community. ${ }^{45}$ In addition, it is important that the government is able to restore confidence in the functioning of society as well as in victims' feeling of safety. Formal health studies provide an insight into the need for healthcare services on the part of victims, and into the actual take up rate of such services. They also serve to reassure people that their problems are being taken seriously. A health study supports the government in instituting appropriate measures to ensure the full physical and mental recovery of persons affected by a disaster.

\section{THE HEALTH EFFECTS OF A DISASTER}

Those affected by a disaster might have to deal with the effects of exposure to certain physical stimuli, as well as toxic agents and psychological stimuli (the subsequent sights, sounds, and smells). These may cause actual physical injury in the short term. Other psychological and physical problems may emerge over time. Such health problems should be seen as "a normal reaction to an abnormal event". ${ }^{6}$

Various health effects may be expected in the longer term. Here, the psychological processing of the disaster is of special significance. In explaining the existence of psychological and physical health problems, "the illusion of invulnerability" plays an important part ${ }^{7}$; the assumed inviolability of one's own life is abruptly contradicted by a disaster. The people affected may then become overly vigilant, overly cautious. The stress that this entails can lead to general psychological and physical complaints, which in many cases have no direct medical explanation. ${ }^{8}$ The desire to suppress unpleasant memories is a significant factor in the development of posttraumatic stress disorder, ${ }^{9}$ other anxiety disorders, depression, and drugs dependency or addiction. ${ }^{4}$

For many victims, the experiences of the disaster play an important part in determining the personal significance of events thereafter. This includes the interpretation of purely physical complaints, which are frequently attributed to possible exposure to physical events or chemical agents at the time of the incident. ${ }^{10}$

Both physical and psychological effects can be evident for several years, after the disaster itself. Unresolved financial concerns that are directly or indirectly related to the incident may form a lingering source of (post-traumatic) stress. Such concerns may impede the psychological processing of the disaster. ${ }^{11}$

If the rest of the community resumes normal life soon after the disaster, this may lead to disillusionment among the victims, as they no longer feel that they enjoy appropriate support and understanding. In the long term, the consequences of the disrupted or insufficient processing of events can be described as the "disaster after the disaster". ${ }^{12}$

The physical and psychological health problems experienced will have certain consequences in terms of the take up rate for healthcare services, and in terms of the social functioning of the people concerned, whether at work, in the family situation, or in other personal interactions. 


\section{SETTING}

In the Netherlands, a Parliamentary Commission appointed after the 1992 Amsterdam air crash, made recommendations concerning the form and content of healthcare services for disaster victims. ${ }^{13}$ Alongside proper care and information services, an important recommendation was that there should be an epidemiological study into possible exposure and the health related effects of the incident. This article describes the form of such a study and the means by which its relation with healthcare services and policy can be established. The study in question was prompted by the explosion of a fireworks depot in Enschede, the Netherlands.

On 13 May 2000, an explosion occurred in a firework storage depot in Enschede, a multicultural and industrial city in the east of the Netherlands with a population of 150000 . The explosion and ensuing fire completely destroyed the surrounding residential district, some 40 hectares in area. Twenty two people were killed outright and almost 1000 were injured. Over 10000 local residents were evacuated for one or more days, while over 1200 people lost their homes completely. An estimated 8000 emergency workers were drafted in to contain the incident, provide immediate aid to victims, and begin initial clearance and reconstruction work. The emergency workers were from the Enschede region, other parts of the Netherlands, and even from neighbouring countries (Germany and Belgium).

Immediately after the disaster, various environmental measurements were conducted. On the basis of these readings, it was not anticipated that the victims would be subject to any special health risks arising from environmental effects. ${ }^{14}$ However, it was also realised that these measurements and the risk assessment were unlikely to assuage the fears of the people concerned. It was further realised that if the remaining uncertainties were not dealt with, the victims would probably attribute any future health problems to the firework disaster, and would therefore demand a specific health study in the future (This had been the case after the 1992 Amsterdam air crash $^{13}$ ).

It quickly became evident that specific aftercare services for those affected by the firework disaster were required, and that the requirement was likely to be long term in nature. To ensure that the services investigated the actual problems and requirements of the target group, it was necessary to collect information concerning their health status and any changes that occurred over time.

\section{STUDY OBJECTIVE}

Having the experience of the 1992 air crash and the recommendations of the Parliamentary Commission, it was quickly decided that information about exposure and possible health consequences should be assessed as soon as possible. The objective of this first assessment was to store information that could not assessed in a later stage. Furthermore, it was decided that the health status of the affected population should be monitored over several years. A framework covering several different health studies was outlined.

The main objective of the total health study is to acquire information for healthcare providers and policy makers to match aftercare services to the problems of the target group. This entails establishing the nature and extent of problems, identifying any high risk groups requiring special attention, and determining the capacity of the required services.

It is not the purpose of the study to provide participants with information concerning individual health effects, although it does perform a function for individual victims in that it shows that there is official recognition of their problems. The health study has a purpose in terms of public policy formulation, as well as a scientific purpose. It provides information that is relevant to future regional and national policy on aftercare services after a disaster, and also offers an opportunity to gain new knowledge concerning the clinical progress of disaster related health problems.

\section{METHODS \\ Participants}

Various groups of people affected by the firework disaster and likely to suffer effects to some extent may be identified. In Enschede, the definition of "victims" was originally rather narrow, being confined to "everyone living or working within the disaster area, and those involved in immediate rescue work". It soon became apparent that this approach was too limited. At the time of the disaster, there were a number of visitors and passers by in the area, while residents of other areas were certainly affected by the disaster. There were also numerous volunteers who took part in the salvage operation. The research project therefore opted for a somewhat broader definition of "persons affected", to include everyone who suffered direct loss or injury as well as those whose exposure was less direct. All such persons were invited to register at the Information and Advice Centre (IAC) that was especially set up for the purpose.

\section{Design}

For the Enschede Firework Disaster Health Monitoring Project, it was decided to combine two research approaches in the framework: a follow up survey among a cohort of victims themselves using questionnaires, and an ongoing monitoring programme whereby health problems are reported by healthcare professionals. Both research types are currently ongoing and are to be conducted for at least four years after the incident of May 2000.

The general follow up survey was conducted on three occasions: three weeks, 18 months, and almost four years after the disaster (see fig 1). The study population was formed immediately after the disaster. All residents of the disaster area received a written invitation to participate, while emergency services personnel were approached through their respective employers. Announcements were also made in the media to recruit victims who could not be reached by mail. The first survey respondents were asked to complete a questionnaire in which the actual exposure to disaster and the psychological impact were assessed. Other questions related to physical and psychological symptoms and relevant background information. Blood and urine samples were taken and were analysed for toxic substances that gave a good indication of possible exposition during the disaster and could be traced in blood and urine three weeks after the disaster. After first analysis, the samples are stored for analysis possibly needed in the future.

At 18 months and almost four years after the disaster the respondents complete a similar questionnaire concerning physical and psychological complaints, and any consequences in terms of their ability to function at work and in social situations. The questionnaires also address the perceived requirement for healthcare services, and the actual take up rate of such services. The follow up surveys were also conducted among a reference group.

In addition to this general follow up research, surveys into more specific aspects are being conducted among subsamples of the study cohort. They include a survey into the effects on children and their families and a follow up study on the emergence and progress of psychiatric disorders. Because a comparatively high number of victims are of Turkish origin a qualitative study is focused on the problems of this group.

The monitoring programme is being conducted with the assistance of general practitioners, the local department of mental health services, occupational health and safety 


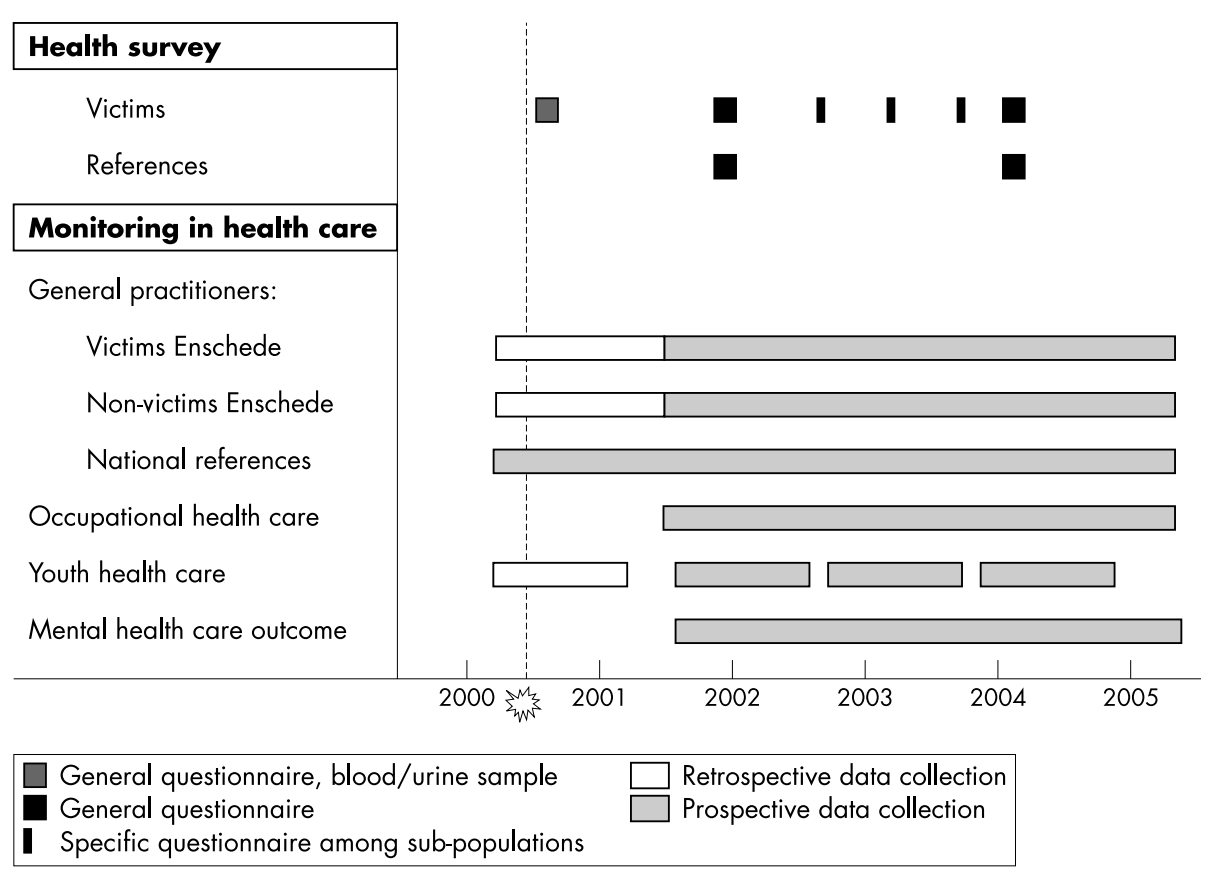

Figure 1 Chronology of the various studies.

services, and the youth healthcare services department (see fig 1).

In the Netherlands, almost everyone has his own general practitioner to whom health problems are initially presented. The general practitioner records all problems, diagnoses, and interventions in an automated registration. Since 2001, all general practitioners in Enschede use the International Classification of Primary Care (ICPC). ${ }^{15}$ The general practitioners also identified those patients who they considered to have been "directly affected" by the incident. There was also cross matching with the existing records of the Information and Advice Centre, whereby two, partially overlapping, groups of patients were marked as victims. The procedure followed is designed to ensure patient privacy, researchers having access to anonymous data only. Patients are able to object to their information being used. The complaints of the "directly affected" patients are compared with those of nonaffected persons from Enschede and with patient information gained by means of a nationwide monitoring programme conducted in the same way. ${ }^{16}$

Most rescue workers deployed in the immediate aftermath of the incident were fire fighters, police, and ambulance crew personnel from the local Twente region. All staff of these emergency services are known to the regional occupational health service, and the names of those deployed during the disaster itself could be obtained from the employers. The occupational health service records all sick leave taken by these personnel, together with the reason. All such information is recorded in a registration system and used anonymously for the purposes of the monitoring project.

Monitoring of children's health was conducted through the youth healthcare services department. All children of school age 4-19 years are systematically examined on a number of occasions, attention being devoted to various aspects of health. The information pertaining to these medical examinations is being used.

After the firework disaster, a specific aftercare centre was created to offer readily accessible care services to those suffering psychological problems as a direct result of the incident. This centre has conducted a study into the clinical progress of complaints and the results of treatment.

\section{Organisation}

The Enschede health study represents scientific research with a social purpose. To ensure appropriate scientific quality, all examinations and surveys are conducted by one of six accredited national scientific institutes. Protocols have been appraised and approved by expert referents and by medical ethics committee. An independent scientific advisory board has been set up for the project, able to offer advice on the studies at any time, whether requested to do so or on its own initiative. The research results are being notified to scientific journals.

Beside scientific quality, social relevance is an important aspect of the study, which must be relevant to aftercare services and must address the questions and issues of the disaster victims themselves. It is also important that the results of the study are available as soon as possible. A social review group is therefore also attached to the project. This comprises both local residents directly affected by the incident and rescue workers, and is also able to offer advice at any stage. The members of the project group have regular contacts with local healthcare providers and policy makers. They are consulted at the start of new activities and are asked to comment on the outline of reports.

A steering group is overseeing the entire project. The project leaders of the different health studies and monitoring projects participate in a project group that coordinates the various activities. A project bureau within the Twente Regional Health Authority (GGD) is responsible for coordinating the implementation of the project in Enschede, and plays an important part in communicating the research results to the participants and to healthcare providers. The project is being funded by the Netherlands Ministry of Health, Welfare and Sport. Personnel capacity of about 27 full time equivalents per annum has been assigned to the project, the annual costs of which are about $€ 2.6$ million.

\section{Communication}

Communication regarding the progress and results of the study represents an important component of the project. Such communication is targeted mainly at the persons directly affected by the firework disaster, healthcare providers, and regional and local policy makers. 
Main conclusions of the first and second health surveys (conducted three weeks and 18 months after the Enschede firework disaster)

First health survey, conducted three weeks after the incident:

- Blood and urine analysis showed no raised concentrations of hazardous substances that may be attributable to the incident (barium, cadmium, chrome, copper, nickel, lead, antimony, strontium, titanium, and zinc).

- A significant proportion of the study group displayed various health problems three weeks after the incident and were limited in their daily activities:

- More than $50 \%$ of residents experienced anxiety, depression and/or other health complaints. Seventy per cent reports re-experiencing the disaster and has avoidance reactions.

- Emergency workers report less frequent reaction. Five per cent reports anxiety, depression and/or other health complaints. Sixteen per cent reports frequent re-experiences and avoidance reactions.

- Persons who had lost loved ones and/or property, had suffered personal injury or who were severely disorientated by the disaster displayed the greatest incidence of health related problems.

Second health survey, conducted 18 months after the incident:

- A significant proportion of the study group continued to display a number of health problems:

- For instance, the 10 most commonly reported health complaints occur in $45 \%-60 \%$ of the affected residents (while $25 \%-48 \%$ of the comparison group report these problems)

- The most common complaints were of pain in the neck and shoulders, general fatigue, and lethargy.

- Over one third (33\%-37\%) of the affected residents reported anxiety, feelings of depression, and hostility (15\%-24\% in the comparison groups).

- $26 \%$ of the residents fulfilled the criteria for the diagnosis of post-traumatic stress syndrome (PTSS).

- For many of the affected residents, their health status improved as compared with the first survey.

- Of those persons currently suffering from PTSS, $40 \%$ were actually receiving treatment.

- Of those persons displaying serious psychological complaints, $20 \%$ had completed a course of treatment or had terminated the treatment prematurely.

In all communication regarding the manner in which the study is being conducted, it is important to be able to explain that this is an epidemiological study, rather than a study of individual patients. For both the disaster victims and the healthcare providers, the usefulness of such an approach may not be immediately evident.

The results of the direct health surveys are published in report form, and are discussed with those taking part. The provisional results of the first survey (based on a random sample) were available just six weeks after the incident. The reports were available for inspection at the information and advice centre, and copies could be ordered. Furthermore, a specific summary of results for the general public was sent to all persons taking part in the survey. The information was also made available through the media (notably the regional television station and the internet site http://www.ggve.nl (at the time in Dutch only). Information evenings have been organised to present and discuss the results with the disaster victims.

The results to date have also been presented separately to healthcare professionals and the municipal executive of the city of Enschede. A number of working conferences for healthcare providers have been organised with a view to implementing the results in the services provided to the disaster victims.

For professionals results will be presented in papers in scientific journals. On our web site (http://www.ggve.nl) a scientific corner in English is available with abstracts and references of papers and reports and background information on the framework.

\section{RESULTS}

The results of the various studies are described in detail elsewhere. The number of affected people is not exactly known. Estimates vary from 8000 to 15000 people, depending on what definition is used. The first health survey (in June 2000) targeted 4192 affected persons, being $41 \%$ local residents, 56\% emergency services personnel, and 3\% visitors (people who happened to be in the disaster area at the time of the incident.) Of these, 3792 returned a completed questionnaire. It is estimated that $30 \%$ of the total number of residents affected by the incident and $8 \%$ to $40 \%$ of the rescue workers deployed at the time of the disaster actually took part in this first health survey. ${ }^{17}$

The second health survey was conducted in November 2001, involving 2851 respondents from the first survey (a $75 \%$ response). The results were published in April 2002. ${ }^{18}$

Data derived from the monitoring by general practitioners, the occupational health service, youth healthcare services department, and the mental health services department first became available in (late) 2002. The relevant information is discussed with general practitioners, health and safety medical officers, psychiatrists, and paediatricians on a quarterly basis. An annual report is also published.

A significant result of the project to date is its effect on the form and content of healthcare services, and on policy. The box presents a number of conclusions arising from the two completed health surveys.

On the basis of the results of the second survey, healthcare providers adapted their working plans and protocols. A campaign was started to encourage people affected by the disaster to seek treatment for their problems. A prevention project was also developed to tackle the problem of prolonged use of sleeping tablets and tranquillisers.

The results of the monitoring programme are regularly discussed with the healthcare providers concerned. Further to the interim findings, the mental health services department has instituted an open surgery in the evening hours. Extra attention is being devoted to the specific problems and needs of the ethic minorities, specialist personnel having been recruited to address this aspect.

\section{DISCUSSION}

This article provides the framework of a research project conducted in the Netherlands with a view to tracking developments in the state of health of persons affected by the firework disaster in Enschede. The study forms an important component of the overall aftercare services provided to this target group. The chosen approach enables proactive anticipation of probable health effects and the resultant requirement for healthcare services.

Although the framework is quite extensive we considered both research approaches necessary because each has its own 
strengths and weaknesses. Together the approaches chosen can make the picture more complete and valid. The follow up survey can provide accurate information concerning individual exposure, together with information concerning health problems as experienced and reported by the victims themselves. The design enables both a repeated cross sectional approach and a longitudinal follow up. However, the basis sample was not a random sample of the affected population. Therefore, the study is susceptible to selective non-response and follow up bias. Moreover, the information is restricted by the content of the questionnaire. Thereby it is possible that asking for certain problems and relating them to the disaster may evoke an over reporting of problems. Finally, it should be noted that this type of study has only a limited number of assessment moments, and that the processing of the results is a comparatively time consuming and expensive undertaking. These restrictions have been found to be particularly problematic by the end users (that is, healthcare professionals and local policy makers) who need actual information concerning current developments.

In our study various surveys are carried out in the same research population, which can lead to excessive demands being placed on the participants.

The monitoring of information via healthcare professionals offers an important complement to the survey component. Registration of information is ongoing, enabling rapid analysis of current developments and immediate notification of results to the user groups. However, certain disadvantages also attach to this monitoring method. It is susceptible to diagnosis bias and diagnosis suspicion bias, as well as some possible interobserver variance. Because the information is taken from third party files and is anonymous (that is, not patient linked), little information is available concerning the actual degree of involvement in the disaster. On the other hand the information is not restricted by the content of a questionnaire. All possible health problems and complaints can be registered, but the registration is restricted to problems, which have led to contact with the healthcare services.

In developing the research project, several practical and organisational limitations and considerations were encountered that may be of relevance to similar studies in the future. It is appropriate to mention some of these obstacles here.

After the disaster it was problematic to identify exactly who has been "directly affected" by the disaster, not at least because of the various possible definitions of "affected". It is difficult to draw any hard line between those who have definitely been affected and those who have definitely not: there will always remain a grey area in which we find people who have been partially or indirectly affected by the incident. ${ }^{19}$ In any study that relies on purely scientific terms of reference, it is possible to limit the scope of the research to those groups with a clear and unarguable exposure, but this approach is far less suited to the aim of arriving at a "community diagnosis".

In Enschede, there was much debate about the area of which inhabitants could be seen as victims. It also took some time to list all inhabitants of this area. It also proved difficult to decide which of the emergency services personnel who had been deployed during the disaster should be considered "affected persons". This is an extremely heterogeneous group with varying levels of involvement in the disaster. It includes for example fire fighters who performed "hands on" rescue work, security personnel deployed to guard property within the disaster area, and volunteers who helped, and in some cases provided accommodation for, the disaster victims. Further groups may be identified, including the families of those directly affected, visitors to the area (passers by), and the staff of businesses engaged for reconstruction work.

Therefore at future disasters, high priority should be given to an adequate registration of the many groups of victims, staff of emergency services, and other persons involved in the incident.

Although the first health survey was conducted very shortly after the incident, other projects were slower to be implemented than might be desired. Most monitoring studies, together with a number of specific health studies, started some 18 months to two years after the disaster. The development of a thorough, well planned research project is a time consuming undertaking, as is its implementation, as this will entail organising cooperative alliances, selecting appropriate research institutes, arranging funding, recruiting personnel, and adapting existing registration systems. In the future other research instruments are needed to make a quick assessment and fulfil the information needs immediately after the disaster.

The main purpose of the project is to acquire information whereby aftercare services can be matched to the problems of the target group. It is important to realise that epidemiological information is one of the factors that will influence policy decisions.$^{20}$ The use of information from research can be promoted when users of the information are involved in the formulation of the research questions. In the first phase of our project, the commitment of healthcare providers and policy makers was inadequately organised. Most of the research questions were formulated by the investigators themselves, based on earlier experiences with other disasters. In a later stage healthcare providers and policymakers participated in the formulation of the research questions and there was more attention paid to the implementation of results into practice. In our experience the research provides information on the problems that need to be addressed. In cooperation with healthcare providers these results should be translated into action. A correlation can now be observed between the results of the study and the development of policy with regard to aftercare services.

It can be argued that our project leads to too much attention on the health problems of victims. On the one hand it has become clear that a disaster causes many problems that should be seen as a health problem and that need specific attention of the healthcare system. On the other hand it should be discouraged that all problems are seen as consequences of the disaster. In our study the data of those who are affected are compared with specific reference groups: inhabitants of a comparable city in the Netherlands or with inhabitants from Enschede who are not a victim of the disaster. Furthermore, at this moment it is discussed how long the monitoring should be continued.

Beside our project and the organised healthcare facilities, in Enschede much attention was paid to projects that promote wellbeing and social cohesion among the victims.

The approach developed in Enschede can be applied in other disasters with similar characteristics: a man made disaster in a western country. Experiences to date have clearly shown that government, policymakers, healthcare providers, and the disaster victims themselves have an ongoing requirement for information concerning the physical and psychological health of the people affected by a disaster. It is notable that this requirement exists even where no physical symptoms attributable to exposure to toxic agents may be expected. It seems advisable to make provisions for this sort of health study as part of the contingency plans for future disasters. In the Netherlands, the preparations for health studies and other support for local authorities are coordinated by the national expertise centres set up for this purpose.

On the other hand every disaster has different characteristics and will generate different information needs. After every new disaster it should be decided what questions need to be addressed in the future and what research strategy is therefore most adequate. Two important topics arise from our 
experience. The first addresses questions on possible exposure and possible impact of the disaster for future health problems. The other question addresses the healthcare needs In the first phase of a disaster information is needed to assess what health care facilities are needed. In a later stage the functioning of the healthcare facilities needs to be monitored in relation with the health problems of victims.

\section{ACKNOWLEDGEMENTS}

The Enschede Firework Disaster Health Monitoring Project has been commissioned by the Netherlands Ministry of Health, Welfare and Sport. Various research institutes contribute, including the National Institute of Public Health and the Environment (RIVM), the Institute for Psychotrauma (IVP), Academic Medical Centre Amsterdam (AMC), the Netherlands Institute for Health Services Research (NIVEL), Institute for Research and Education in Mental Health Twente (STOOGG), and the Youth Healthcare Services department of the Twente Regional Health Authority (GGD Regio Twente). GGD Regio Twente is also responsible for the coordination of the individual studies which make up the Health Monitoring Project.

\section{Authors' affiliations}

J Roorda, W A H J van Stiphout, R R R Huijsman-Rubingh, Enschede Firework Disaster Health Monitoring Project, Netherlands R R R Huijsman-Rubingh, Netherlands Ministry of Health, Welfare and Sport

Conflicts of interest: none declared.

For the Enschede Firework Disaster Health Monitoring Project steering committee and project group: J G A Derks, J Roorda, K Smit, GGD Regio Twente (Regional Health Authority), Enschede, Netherlands; R R R Huijsman-Rubingh, Netherlands Ministry of Health, Welfare and Sport, The Hague, Netherlands; W A H J van Stiphout, Stjohout Training in Practice (STIP), Zweelo, Netherlands; E Lebret, J Meulenbelt, L Grievink, National Institute of Public Health and the Environment (RIVM), Bilthoven, Netherlands; B P R Gersons, M L Meewisse, Academic Medical Centre (AMC), Amsterdam, Netherlands; P G van der Velden Institute for Psychotrauma (IVP), Zaltbommel, Netherlands; C J Yzermans, Netherlands Institute for Health Services Research (NIVEL), Utrecht, Netherlands; E L Noorthoorn, Mediant/Institute for Research and Education in Mental Health (STOOGG), Enschede, Netherlands.

\section{REFERENCES}

1 Noji EK. The public health consequences of disasters. Prehospital Disaster Med 2000; 15:147-57
2 Cullinan P, Acquilla SD, Dhara VR. Long term morbidity in survivors of the 1984 Bhopal gas leak. Natl Med J India 1996;9:5-10.

3 Dhara VR, Gassert TH. The Bhopal syndrome: persistent questions about acute toxicity and management of gas victims. Int J Occup Environ Health 2002;8:380-6.

4 Bromet EJ, Havenaar JM. Mental health consequences of disasters. In: Sartorius N, Gaebel W, López-lbor MM, eds. Psychiatry in society. London: Wiley, 2002:241-62.

5 Bromet EJ, Dew MA. Review of psychiatric epidemiologic research on disasters. Epidemiolc Rev 1995; 17:113-19.

6 Gersons BPR, Carlier IVE. Plane crash crisis intervention: a preliminary report from the Bijlmerramp, Amsterdam. Journal of Crisis Intervention and Suicide Prevention 1993:14:109-16.

7 Jasnoff-Bulman $\mathbf{R}$. The benefits of illusions, the threat of disillusionment and the limitations of inaccuracy. Journal of Social and Clinical Psychology 1989;8:158-75.

8 Barsky AB, Borus JF. Functional somatic syndromes. Ann Intern Med $1999 ; 130: 910-21$.

9 Gersons BPR, Carlier I. Post-traumatic Ssress disorder: the history of a recent concept. Br J Psychiatry 1992;161:742-8.

10 Donker GA, Yzermans CJ, Spreeuwenberg $P$, et al. Symptom attribution after a plane crash: comparison between self- reported symptoms and GP records. Br J Gen Pract 2002;52:917-22.

11 Kleber RJ, Brom D. Coping with trauma; theory, prevention and treatment. Lisse: Swets and Zeitlinger, 1992.

12 Raphael B. When disaster strikes: a handbook for the caring professions. Boston: Unwin Hyman, 1986.

13 Yzermans CJ, Gersons BPR. The chaotic aftermath of an airplane chrash in Amsterdam. In: Havenaar JM, Cwikel JG, Bromet EJ, eds. Toxic turmoil: psychological and societal consequences of ecological disasters. New York: Kluwer Academic/Plenum, 2002:85-99.

14 Mennen MG, Kliest JJG, van Bruggen M. Vuurwerkramp Enschede: Metingen van concentraties, verspreiding en depositie van schadelijke stoffen: rapportage van het milieuonderzoek. [The Enschede firework disaster: measurements of concentrations, distribution and deposits of hazardous substances]. Report no: 609022 002. Bilthoven: RIVM, 2001.

15 Lamberts $\mathbf{H}$, Wood $M$. The international classification of primary care (ICPC). Oxford: Oxford University Press, 1986.

16 Schellevis FG, Westert GP, de Bakker DH. De Tweede nationale studie naa ziekten en verrichtingen in de huisarstenpraktiik; aanleiding en methoden. [Second national study of presentations and interventions in general practice: background and methods]. Huisarts en Wetenschap 2003;46:7-12.

17 van Kamp I, van der Velden PG. Vuurwerkramp Enschede: Lichamelijke en geestelijke gezondheid en ervaringen met de ramp; rapportage van het gezondheidsonderzoek, [Physical and mental health and experiences of the disaster]. Report no: 630930 002/99. Bilthoven: RIVM, 2001.

18 van der Velden PG, Grievink L, Dusseldorp A, et al. Gezondheid Getroffenen Vuurwerkramp Enschede, [The health of the victims of the Enschede firework disaster]. Report no 630930004. Bilthoven: RIVM, 2002

19 Wright KM, Ursano RJ, Bartone PT, et al. The shared experience of catastrophe: an expanded classification of the disaster community. Am J Orthopsychiatry 1990;60:35-42.

20 de Leeuw E. Health policy, epidemiology and power: the interest web. Health Promotion International 1993;8:49-52. 
BOOK REVIEWS

La utilización de las evidencias en las decisiones de política sanitaria (The use of the evidence in health policy decisions)

Edited by $\mathrm{E}$ Regidor. Alicante: Alicante University, 2003, pp 270. ISBN 84-6881893-3

This book is the result of a seminar held in April 2003 by the University of Alicante (Spain). The publisher and entire support team have made every effort to give the articles written by different authors a homogeneity rare in works of a similar origin.

For some years, the health system, both the professionals working in it and the users and those responsible for its management, have been debating whether the decisions taken have a scientific basis.

However, some fields seem to be outside this movement causing some perplexity in the observer. One of these fields is public health and, precisely, health management. As discussed in the first chapter of this book, it is a field in which the evidence is scarce and contradictory and, in that framework, little can be done by those with the task of decision taking to give support to evidence that, very often, is no such thing.

The book has 10 chapters, with the first one dedicated to giving the reader a general view of the matter in question-the use of evidence applied to public health measures. The other nine contributions consider different examples of public health problems with their characteristics and-why not say so?with their contradictions.

We are given interesting material for a debate as the decisions in this field are influenced not only by the scientific evidence, in many cases arguable as mentioned previously, but also by other factors of a social, cultural, and economic nature that cannot be forgotten

Antonio Cueto Espinar

\section{When food kills: BSE, E coli and disaster science}

Edited by $\mathrm{T} H$ Pennington. Oxford: Oxford University Press, 2003, £25.00, pp 226. ISBN 0-198-52517-6

Pennington delivers serious messages in this discursive, thought provoking book by sharing his insight into the failings of food safety (and other) inspectorates. Few have forgotten the hysteria associated with the Escherichia coli 0157 outbreak in central Scotland (linked to Barr's butchers) or the salmonella in eggs scare when Edwina Currie was Parliamentary Under-Secretary for Health. The situations leading to these and other food poisoning and public health scares are eloquently described throughout, alongside a narrative on the apparent failures of government officials to learn from history through subsequent presentation of new health scares. It is proposed that $\mathrm{VCJD}$ cases in humans and BSE cases in animals are a result of these failures. Details regarding the scientific uncertainties over cause, transmission, and scope of these diseases are discussed prior to the UK government's early assumption that BSE was not likely to be of risk to human health, the future risks to human health from VCJD, and the conclusions of the Phillips inquiry into methods used so far to eradicate BSE and VCJD.

The title indicates that food related incidents will be the principal subject of discussion; however this is not the case. Inferences are drawn throughout from events including the Aberfan tip mining disaster, the Piper Alpha North Sea oil disaster, and even the conditions within lunatic asylums since 1815 . Repeated and detailed references to non-food disasters with catastrophic potential through high morbidity and mortality levels, as compared with the innocuous/unknown long term health problems associated with food scares like BSE somewhat trivialises the importance to public health of food safety scares, and renders the title misleading. Essentially, this is a non-technical book that describes (with reference to $E$ coli, BSE, and other disasters) the history, the science, the politics, and most significantly, what went wrong. It may leave the reader concerned by the inspectorates' shortcomings in the mitigation of public health incidents, but delivers an important message: inclusiveness and openness are essential to help avert wide scale disasters in the future.

\section{Claire E Robertson}

\section{Health and community design: the impact of the built environment on physical activity}

Edited by L Frank, $\mathrm{P}$ Engelke, T Schmid. Washington, DC: 2003, \$30.00, pp 253. ISBN 1-55963-917-2

Sedentary behaviour is a major cause of poor health worldwide both through the direct effects of inactivity on health and indirectly via its contribution to obesity. Health and Community Design describes the role of the built environment as a potential contributor to physical inactivity and suggests ways in which communities could be structured to encourage or require physical activity, particularly walking and bicycling.

The "built environment" is defined broadly as "...the form and character of communities" encompassing land use patterns, urban design characteristics, and transportations systems. Frank et al emphasise the influence of the built environment on physical activity and they effectively describe its potential role as a determinant of obesity. However, obesity is likely to be influenced by factors in addition to physical activity, particularly diet. This book highlights the need for a comprehensive assessment of how the built environment influences diverse determinants of energy balance, including diet, and other health behaviours. Occasionally, the authors neglect potential trade offs associated with choices concerning community design. For example, cul de sacs may decrease walking by adults but increase outdoor play of children. Understanding such trade offs is critical to improve planning and prioritisation among design choices.

All in all, we strongly recommend this book as an introduction to connections between urban planning and sedentary behaviour. The authors have done an outstanding job presenting arguments that can be made linking the built environment and physical activity and these arguments should be of great interest to public health, transportation and urban design researchers and planning professionals. The text is also accessible enough for community activists interested in understanding potential consequences of planning decisions and its maps and illustrations are particularly novel and effective for a public health audience.

Brooke Fischer, Sarah Dash, David Berrigan

\section{Health measurement scales. A practical guide to their development and use, 3rd ed}

Edited by David L Streiner, Geoffrey R Norman. Oxford: Oxford University Press, 2003, $£ 26.50$, pp 283. ISBN 0-19852-947-7

This is the third edition of a successful book whose previous two editions were published in 1989, and 1994. It is a practical guide about health measurement scales called as well "latent outcomes", such as cognitive abilities, attitudes, quality of life, etc, addressed to clinicians, users. and developers of health measurement scales.

In this third edition the authors have updated most of the chapters, mainly those related to cognitive requirements in answering questions, and include a more in depth chapter on item response theory.

The general content of the book follows the process of development and evaluation of health measurement scales. Chapters are devoted to the process of scale development, which includes basic concepts, how to devise and select items, and building scales. Chapters addressed to analyse attributes of the measures include reliability and validity, as well as measuring change. The chapter about ethical issues that researchers should take into account in their own fieldwork is also of valuable interest. Most chapters are accompanied by practical examples and a considerable number of tables and figures that make easy to understand and to interpret what authors want to explain. Appendices include commented bibliography and recommended reading, sources of developed scales, and a short introduction to exploratory and confirmatory factor analysis.

Through the whole book, authors also try to clarify their point of view on controversial 
concepts and present issues that are in the centre of the debate in scientific literature.

In summary, it is a highly recommended book for those not psychometric experts but users or developers of questionnaires in the area of health sciences. It is an essential reading for those who start working in this area. I am sure that it will be as successful as the previous two editions.

Luis Rajmil

\section{Community-based health research. Issues and methods}

Edited by Daniel S Blumenthal, Ralph J Di Clemente. Springer Publishing, 2003, \$39.95 (USA), $\$ 44.80$ (other countries), pp 218. ISBN 0-8261-2025-3

This book is a very interesting referent document for those who work in the public health research field. In fact it is more appropriate for researchers with some experiences in doing public health research rather than junior students. The readers can find some actual examples with in depth analysis on each case, which is very useful for them However these examples and illustrations are more focused on American and African countries, so that it weakens the global and international application of the book

Strengths: one of the strengths of this book is to identify and synthesise the key issues and principles for working with communities. It can be used as a theoretical frame for training courses on community based research. The contribution of this book is to emphasise the importance of community based research, which sometimes is forgotten by traditional epidemiological study. It also brings the sight and attention to the involvement of the community to research, change their role from target group to co-researcher, and from positive to active involvement.

Weaknesses: the authors tried to prepare a comprehensive document on community based research, which included all the issues like introduction, principles, methods, and examples/experiences. But the readers, after looking at the title of the book, are more interested in learning more specific issues and methods for community based research and in how to distinguish it from public health research in general. It would have been more interesting if the authors had clarified more clearly the differences in methodology applications in epidemiological and community based research.

Dao Lan Huong

Table 5 (corrected) Association of disease severity, standardised for age and sex, with socioeconomic position using individual and area level measures

\begin{tabular}{|c|c|c|c|c|c|c|c|c|}
\hline \multirow{2}{*}{$\begin{array}{l}\text { Socioeconomic } \\
\text { position }\end{array}$} & \multicolumn{2}{|c|}{ Social class } & \multicolumn{2}{|c|}{$\begin{array}{l}\text { Educational } \\
\text { attainment }\end{array}$} & \multicolumn{2}{|c|}{$\begin{array}{l}\text { Income } \\
\text { category }\end{array}$} & \multicolumn{2}{|c|}{$\begin{array}{l}\text { ED level Townsend } \\
\text { score quantile }\end{array}$} \\
\hline & $\mathbf{n}$ & mean (SE) & $n$ & mean (SE) & $n$ & mean (SE) & $n$ & mean (SE) \\
\hline 1 (most deprived) & 42 & $15.6(2.5)$ & 430 & $16.5(2.8)$ & 177 & $17.0(3.1)$ & 190 & $16.0(3.0)$ \\
\hline 2 & 175 & $16.0(3.0)$ & 69 & $17.5(2.8)$ & 268 & $17.2(2.5)$ & 191 & $16.2(3.0)$ \\
\hline 3 & 436 & $16.2(2.9)$ & 90 & $14.7(5.6)$ & 212 & $15.9(2.8)$ & 190 & $15.9(2.8)$ \\
\hline 4 & 261 & $15.8(2.9)$ & 177 & $15.6(2.7)$ & 115 & $15.0(2.6)$ & 189 & $16.1(2.8)$ \\
\hline 5 (most affluent) & 40 & $15.7(2.7)$ & 188 & $15.3(2.9)$ & 182 & $14.0(2.2)$ & 194 & $15.8(2.8)$ \\
\hline $\begin{array}{l}\text { Correlation } \\
\text { coefficientt ( } p \text { value) }\end{array}$ & \multicolumn{2}{|c|}{$-0.10(<0.01)$} & \multicolumn{2}{|c|}{$-0.07(0.03)$} & \multicolumn{2}{|c|}{$-0.09(<0.01)$} & \multicolumn{2}{|c|}{$0.07(0.03)$} \\
\hline & \multicolumn{2}{|c|}{$\begin{array}{l}5.63 \\
(2.23 \text { to } 9.04)\end{array}$} & \multirow{2}{*}{\multicolumn{2}{|c|}{$\begin{array}{l}3.79 \\
(0.41 \text { to } 7.18)\end{array}$}} & \multirow{2}{*}{\multicolumn{2}{|c|}{$\begin{array}{l}5.05 \\
(1.78 \text { to } 8.32) \\
<0.01\end{array}$}} & \multirow{2}{*}{\multicolumn{2}{|c|}{$\begin{array}{l}4.04 \\
(-0.04 \text { to } 8.13) \\
0.05\end{array}$}} \\
\hline test for trend $p$ value & $<0.0$ & & & & & & & \\
\hline
\end{tabular}

${ }^{*} \mathrm{p}<0.05 ;{ }^{* *} \mathrm{p}<0.01$. †Spearman's rank correlation.

\section{CORRECTIONS}

There were two author errors (one terminological and one relating to data ) in this paper by Dr Eachus and others (1999;53:603-11). Firstly, the authors referred to the index relating socioeconomic position to New Zealand score of severity of hip disease as the relative index of inequality, whereas the statistic presented is actually the slope index of inequality. Secondly, a programming error led to miscalculation of the correlation coefficients and slope indices of inequality presented in table 5. A corrected table is presented here. The direction of associations is the same as for the incorrect results presented in the original paper, but the effect sizes and significance level are both substantially greater when the correct data are seen, in particular for the associations of social class and Townsend deprivation score with hip disease severity. In the light of the correct data the discussion that was included on why the social class association was weak is no longer applicable.

\section{doi: 10.1136/jech.2003.014613corr l}

The authors would like to clarify some points in this paper $(2004 ; 58: 982-7)$. The results and conclusions presented in the box on page 985 are preliminary and based on earlier published reports in Dutch.[1-3] This information is merely intended to illustrate the information needs of healthcare providers after a disaster. Details of the health problems of the affected groups and their use of health care will be published in other papers.
1. RIVM Project Team. Firework disaster Enschede: components in blood and urine (Dutch report). Bilthoven, Netherlands: National Institute of Public Health and the Environment (report no 630930003), 2001.

2. van Kamp I, van der Velden PG. Vuurwerkramp Enschede: Lichamelijke en geestelijke gezondheid en ervaringen met de ramp; rapportage van het gezondheidsonderzoek [Physical and mental health and experiences of the disaster]. Bilthoven, Netherlands: National Institute of Public Health and the Environment (RIVM) and Institute for Psychotrauma (IVP), (report no RIVM 630930002/ IVP 9920012), 2001.

3. van der Velden PG, Grievink L, Dusseldorp, et al. Gezondheid Getroffenen Vuurwerkramp Enschede; rapportage gezonheidsonderzoek 18 maanden na de ramp. [Health (status) of the victims of the Enschede firework disaster 18 months after the disaster]. Zaltbommel, Netherlands: Institute for Psychotrauma (IVP) and National Institute of Public Health and the Environment (RIVM), (report no RIVM 630930004/ IVP 9920023), 2002.

\section{doi: 10.1136/jech.2004.022871corr 1}

There were two author errors in this letter by I D K Dimoliatis (2004;58:1054-5). The unit of measurement in the title should be in lower case (qy) [not (QY)]. Also, in line three of the second paragraph it should read $(80 y-50 y)$ [not $80 y-30 y$ ]. 